\title{
Bird Flu and Bangladesh: Review and Update
}

\section{ASM NU AHMED}

\begin{abstract}
Summary:
Bird flu is an infectious disease of birds caused by Influenza A (H5N1) virus. Although the virus usually do not infect humans, more than 200 confirmed human casess of Avian Influenza $A$ have been reported worldwide. Almost all of them had caught it from birds. While H5N1 undergoes specific mutations and reassorting creating variations which can infect species not previously known to carry the virus, health experts fear the virus could trigger a pandemic if it mutates to form a strain that can transmit between humans. As bird flu confirmed in about 59 countries, it is extremely pathogenic, humans do not possess any immunity to it, currently no vaccine is available and sometimes H5N1
\end{abstract}

\section{Introduction:}

The dreaded Avian Influenza virus, better known as 'bird flu', has been detected at Savar on the outskirts of the capital Dhaka. The Bangladesh government announced the detection of the Avian Influenza on Thursday, 22nd March 2007; samples were sent to the Bangladesh Livestock Research Institute and also to the National Institute of Animal Health in Bangkok, which confirmed the presence of the deadly H5N1 strain of the virus. ${ }^{1}$ The virulent $\mathrm{H} 5 \mathrm{~N} 1$ virus has killed at least 169 people across the world since late 2003 through contact with infected birds, according to the World Health Organization (WHO). ${ }^{2}$ Blood samples of a number of workers at the farms, where the deadly virus was confirmed among chickens, tested negative for the virus. ${ }^{3}$ It is unclear how poultry became infected at the farm in Savar town, about $40 \mathrm{~km}$. west of Dhaka. Bangladesh, home to hundreds of thousands of poultry farms, has already banned import of poultry products from more than 50 countries as part of a preventive measure to check bird flu from entering the country. Despite all the precautionary measures, its entry could not be stopped finally.

The authorities concerned have reportedly taken a few emergency steps to stop spread of the disease and

Address of correspondence: Dr. A.S.M. Nawshad Uddin Ahmed, FCPS, Associate Professor of Paediatrics, Kumudini Women's Medical College, Mirzapur, Tangail, Mobile: 01552-372200, Email: dr_nawshad@yahoo.com

Received: 09 April, 2007

Accepted: 01 October, 2007 can become resistant to the antivirals, a global pandemic would kill millions of people. A human pandemic would be particularly catastrophic in developing countries where living conditions and malnutrition are likely to make people more vulnerable, health services are weak and vaccines and antivirals would be beyond reach. Recently bird flu has been detected in Bangladesh, which may lead to devastating consequences on the health of the people and economy of the country. So every effort should be taken to prevent its further spread, make people aware of the disease, training health personnel and stockpiling antivirals to face any human epidemic.

(J Bangladesh Coll Phys Surg 2008; 26: 32-38)

advised the people not to be panicked by the news of the disease and continue consuming cooked poultry meat and boiled or fried eggs as usual. Since then bird flu has been reported in 12 districts both in organized and backyard poultry. To mitigate further spread the authorities, meanwhile, have culled more than 100,000 poultry in the affected regions. ${ }^{4}$ Besides, decision has been taken to destroy all poultry birds within one kilometer radius of any affected area to contain the disease. The members of the armed forces have cordoned the risk zone to stop any attempt to smuggle out poultry birds from there. Other measures include health checks on all workers who may have come into contact with the infected birds. ${ }^{3}$ So far there has been no human case of bird flu in Bangladesh.

\section{The Avian Influenza A (H5N1) virus:}

Avian Influenza is an infectious disease of birds caused by Influenza A (H5N1) virus,- also called 'H5N1 virus' - occurs mainly in birds, is highly contagious among birds, and can be deadly to them. ${ }^{5} \mathrm{H} 5 \mathrm{~N} 1$ is a subtype of the species Influenza A virus of the Influenzavirus $A$ genus of the Orthomyxoviridae family. Like all other Influenza A subtypes, the H5N1 subtype is an RNA virus. $^{6}$ (Fig. 1) Infected birds shed Influenza virus in their saliva, nasal secretions, and feces; the virus can survive for considerable lengths of time outside of the host. Susceptible birds become infected when they have contact with contaminated secretions or 
excretions or with surfaces that are contaminated with secretions or excretions from infected birds. Domesticated birds, including chickens, ducks, and turkeys, may become infected with Avian Influenza virus through direct contact with infected waterfowl or other infected poultry, or through contact with surfaces (such as dirt or cages) or materials (such as water or feed) that have been contaminated with the virus. ${ }^{5}$ Infection with Avian Influenza viruses in domestic poultry causes two main forms of disease that are distinguished by low and high extremes of virulence. The 'low pathogenic' form may go undetected and usually causes only mild symptoms (such as ruffled feathers and a drop in egg production). However, the 'highly pathogenic' form spreads more rapidly through flocks of poultry. This form may cause disease that affects multiple internal organs and has a mortality rate that can reach $90-100 \%$, often within 48 hours. ${ }^{7}$

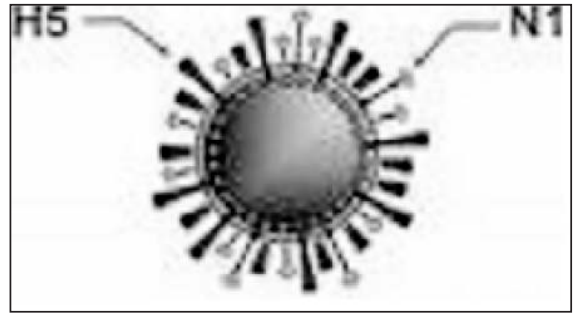

Fig. 1: H5N1 virus

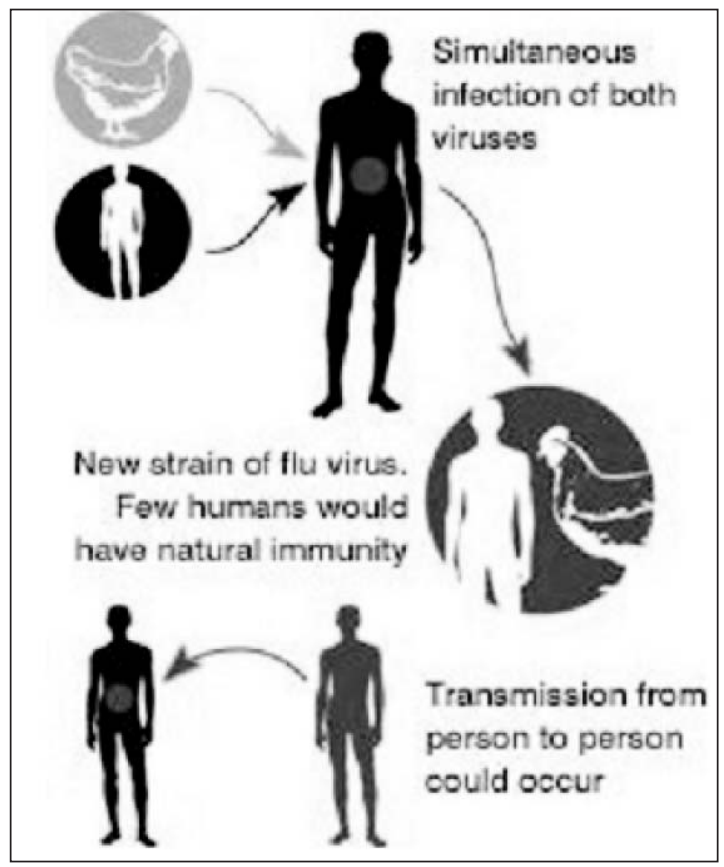

Fig. 2: If a person were infected with avian and human flu viruses at the same time, they could swap genes creating a new strain transmissible between humans.
Avian Influenza A (H5N1) virus that has been reported from Africa, Asia, Europe, and the Near East:

The disease, which was first identified in Italy more than 100 years ago, now occurs worldwide. Since December 2003, Avian Influenza A (H5N1) infections in animals have been reported in Asia, Africa, the Pacific, Europe, and the Near East. Outbreaks of Avian Influenza H5N1 occurred among poultry in eight countries in Asia (Cambodia, China, Indonesia, Japan, Laos, South Korea, Thailand, and Vietnam) during late 2003 and early $2004 .^{8}$ At that time, more than 100 million birds in the affected countries either died from the disease or were killed in order to try to control the outbreaks. By March 2004, the outbreak was reported to be under control.

Beginning in June 2004, however, new outbreaks of Influenza H5N1 among poultry and wild birds were reported in Asia.9,10 Since that time, the virus has spread geographically. Reports of H5N1 infection in wild birds in Europe began in mid 2005. In early 2006, Influenza A H5N1 infection in wild birds and poultry were reported in Africa and the Near East. ${ }^{11}$

How is Avian Influenza detected in birds:

Tests for diagnosing all Influenza strains of animals are rapid and reliable. Many laboratories in the WHO global Influenza network have the necessary highsecurity facilities and reagents for performing these tests as well as considerable experience.

What animals can be infected with Avian Influenza A (H5N1) viruses:

In addition to birds, pigs, tigers, leopards, ferrets, and domestic cats can be infected with Avian Influenza A (H5N1) viruses. ${ }^{12}$ In addition, in early March 2006, Germany reported H5N1 infection in a stone marten (a weasel-like mammal). The Avian Influenza A (H5N1) virus that emerged in Asia in 2003 is evolving and it is possible that other mammals may be susceptible to infection as well. Centers for Disease Control and Prevention (CDC), USA is working closely with domestic and international partners to continually monitor this situation and will provide additional information to the public as it becomes available. ${ }^{13}$ 


\section{Do bird flu viruses infect humans:}

Although Avian Influenza A viruses usually do not infect humans, the first documented infection of humans with an Avian Influenza virus occurred in Hong Kong in 1997, when the H5N1 strain caused severe respiratory disease in 18 humans, of whom 6 died. ${ }^{14,15}$ The infection of humans coincided with an epidemic of highly pathogenic Avian Influenza, caused by the same strain, in Hong Kong's poultry population. ${ }^{14}$ Since January 2004, the World Health Organization has reported human cases of Avian Influenza A (H5N1) in Asia, Africa, the Pacific, Europe, and the Near East. Since then more than 306 confirmed cases of human infection with Avian Influenza A (H5N1) viruses have been reported, more than half of those people reported infected with the virus have died. ${ }^{10}$ Most cases have occurred in previously healthy adults and children, and some with chronic medical conditions and have resulted from direct or close contact with H5N1-infected poultry or H5N1-contaminated surfaces.

In general, H5N1 remains a very rare disease in humans. The H5N1 virus does not infect humans easily, and if a person is infected, it is very difficult for the virus to spread to another person. While there has been some human-to-human spread of H5N1, it has been limited, inefficient and unsustained. ${ }^{16}$ For example, in 2004 in Thailand, probable human-tohuman spread in a family resulting from prolonged and very close contact between an ill child and her mother was reported. ${ }^{16,17}$ Most recently, in June 2006, WHO reported evidence of human-to-human spread in Indonesia. In this situation, 8 people in one family were infected. The first family member is thought to have become ill through contact with infected poultry. This person then infected six family members. One of those six people (a child) then infected another family member (his father). No further spread outside of the exposed family was documented or suspected. ${ }^{5,11}$

\section{What are the implications of Avian Influenza to} human health:

Thus two main risks for human health from Avian Influenza are 1) the risk of direct infection when the virus passes from the infected bird to humans, sometimes resulting in severe disease; and 2) the risk that the virus - if given enough opportunities - will change into a form that is highly infectious for humans and spreads easily from person to person. ${ }^{18}$

\section{Why H5N1 is of particular concern:}

Of the 15 Avian Influenza virus subtypes, H5N1 is of particular concern for several reasons. H5N1 mutates rapidly and has a documented propensity to acquire genes from viruses infecting other animal species. ${ }^{19}$ Its ability to cause severe disease in humans has now been documented on two occasions. ${ }^{2,10}$ In addition, laboratory studies have demonstrated that isolates from this virus have a high pathogenicity and can cause severe disease in humans. Birds that survive infection excrete virus for at least 10 days, orally and in faeces, thus facilitating further spread at live poultry markets and by migratory birds.

\section{What are the symptoms of Avian Influenza in humans:}

Published information about the clinical course of human infection with H5N1 Avian Influenza is limited to studies of cases in the 1997 Hong Kong and 2004 Thailand outbreaks. ${ }^{10,14,20}$ The reported symptoms of Avian Influenza in humans have ranged from typical human Influenza- like symptoms (fever, cough, sore throat, and muscle aches) to eye infections, pneumonia (with chest radiograph changes), severe respiratory diseases (such as acute respiratory distress syndrome) leading to respiratory failure requiring intubation, and other severe and lifethreatening complications.

How is Avian Influenza detected in humans: Avian Influenza cannot be diagnosed by symptoms alone, so a laboratory test is required. Avian Influenza is usually diagnosed by collecting a swab from the nose or throat during the first few days of illness. This swab is then sent to a laboratory, where they will either look for Avian Influenza virus using a molecular test, or they will try to grow the virus. ${ }^{21,22}$ Growing Avian Influenza viruses should only be done in laboratories with high levels of protection. If it is late in the illness, it may be difficult to find an Avian Influenza virus directly using these methods. If this is the case, it may still be possible to diagnose Avian Influenza by looking for evidence of the body's response to the virus. This is not always an option because it requires two blood specimens (one 
taken during the first few days of illness and another taken some weeks later), and it can take several weeks to verify the results. ${ }^{23}$

\section{How is Avian Influenza in humans treated:}

Studies done in laboratories suggest that the prescription medicines approved for human Influenza viruses should work in treating Avian Influenza infection in humans. Four different Influenza antiviral drugs (amantadine, rimantadine, oseltamivir, and zanamivir) are approved by the U.S. Food and Drug Administration (FDA) for the treatment and prevention of Influenza. ${ }^{24,25}$ All four have activity against Influenza A viruses. However, sometimes Influenza strains can become resistant to these drugs, and therefore the drugs may not always be effective. For example, analyses of some of the 2004 H5N1 viruses isolated from poultry and humans in Asia have shown that the viruses are resistant to two of the medications (amantadine and rimantadine). ${ }^{26}$ Two other antiviral medications (oseltamivir and zanamavir) would probably work to treat Influenza caused by $\mathrm{H} 5 \mathrm{~N} 1$ virus, but additional studies are needed to demonstrate their current and ongoing effectiveness.

\section{Threat of a global pandemic:}

Nonetheless, because all Influenza viruses have the ability to change, scientists are concerned that H5N1 virus one day could be able to infect humans and spread easily from one person to another. 27,28 Because these viruses do not commonly infect humans, there is little or no immune protection against them in the human population. A human pandemic could start in two ways. If a person were infected with Avian and human flu viruses at the same time they could swap genes creating a new strain transmissible between humans. ${ }^{18}$ (Fig. 2) In this case it would spread very rapidly. Alternatively, the virus could adapt more gradually, improving its ability to bind to human cells during repeated human infection. If $\mathrm{H} 5 \mathrm{~N} 1$ virus were to gain the capacity to spread easily from person to person, an Influenza pandemic (worldwide outbreak of disease) could begin.

No one can predict when a pandemic might occur. However, experts from around the world are watching the H5N1 situation in Asia and Europe very closely and are preparing for the possibility that the virus may begin to spread more easily and widely from person to person.

\section{Is there a vaccine to protect humans from H5N1 virus:}

There is currently no commercially available vaccine to protect humans against the $\mathrm{H} 5 \mathrm{~N} 1$ virus that is being detected in Asia and Europe. No vaccine is available because there is no way to predict what the pandemic strain will look like. It takes at least six months to make a new flu vaccine once the virus has appeared. ${ }^{29}$ However, CDC continues to work with WHO and the National Institutes of Health (NIH) on development of a vaccine for Influenza A (H5N1). Research studies to test a vaccine that will protect humans against H5N1 virus began in April 2005, and a series of clinical trials is under way. ${ }^{30}$

\section{Is there a risk for becoming infected with Avian Influenza by eating poultry:}

There is currently no scientific evidence that people have been infected with bird flu by eating safely handled and properly cooked poultry or eggs. Even if poultry and eggs were to be contaminated with the virus, proper cooking would kill it. ${ }^{31}$ In fact, recent studies have shown that the cooking methods that are already recommended by the U.S. Department of Agriculture (USDA) and the Food and Drug Administration (FDA) for poultry and eggs to prevent other infections will destroy Influenza viruses as well. ${ }^{32}$

So to stay safe, the advice is the same for protecting against any infection from poultry:

Wash your hands with soap and warm water for at least 20 seconds before and after handling raw poultry and eggs.

Clean cutting boards and other utensils with soap and hot water to keep raw poultry from contaminating other foods.

Use a food thermometer to make sure you cook poultry to a temperature of at least 165 degrees Fahrenheit. Consumers may wish to cook poultry to a higher temperature for personal preference.

Cook eggs until whites and yolks are firm.

Is there travel restrictions to areas with known H5N1 outbreaks:

CDC does not recommend any travel restrictions to affected countries at this time. However, CDC 
currently advises that travelers to countries with known outbreaks of H5N1 Influenza avoid poultry farms, contact with animals in live food markets, and any surfaces that appear to be contaminated with feces from poultry or other animals. ${ }^{33}$

\section{Bird import ban:}

There is currently a ban on the importation of birds and bird products from $\mathrm{H} 5 \mathrm{~N} 1$-affected countries. The regulation states that no person may import or attempt to import any birds (Class Aves), whether dead or alive, or any products derived from birds (including hatching eggs), from the specified countries.

\section{Control measures:}

The quarantining of infected farms and destruction of infected or potentially exposed flocks are standard control measures aimed at preventing spread to other farms and eventual establishment of the virus in a country's poultry population. ${ }^{34}$ Apart from being highly contagious, Avian Influenza viruses are readily transmitted from farm to farm by mechanical means, such as by contaminated equipment, vehicles, feed, cages, or clothing. Highly pathogenic viruses can survive for long periods in the environment, especially when temperatures are low. Stringent sanitary measures on farms can, however, confer some degree of protection.

In the absence of prompt control measures backed by good surveillance, epidemics can last for years. For example, an epidemic of H5N2 Avian Influenza, which began in Mexico in 1992, started with low pathogenicity, evolved to the highly fatal form, and was not controlled until 1995. ${ }^{35}$

\section{Is Bangladesh ready to face an epidemic:}

Bangladesh has started its preparedness to combat against bird flu from 2005. 'National Avian Influenza and Human Pandemic Influenza Preparedness and Response Plan Bangladesh 2006-2008' was approved by the Government of bangladesh in 2006 as a preparedness for any bird flu outbreack. ${ }^{4}$ There is detailed plans for prevention and measures to be taken during any epidemic. Government has already started mass campign to increase public awareness about the disease, training health care personnel, stockpiled antiviral drugs and other supportive medications and equipments for management and prophylaxis. Vaccines for seasonal influenza are also being stockpiled for health care workers and initiative has been taken to set up a modern influenza referral laboratory. ${ }^{4}$

\section{Conclusion:}

The dreaded Avian Influenza virus has claimed many lives and played havoc with poultry industry in some countries of Asia and Europe, was also detected in neighbouring India and Myanmar only recently. Despite all the precautionary measures, its entry into our country could not be stopped finally. Health experts fear the virus could trigger a pandemic if it mutates to form a strain that can transmit between humans. The Asian Development Bank says even a mild pandemic could kill 3 million in Asia alone and cost the region $\$ 300$ billion. ${ }^{35}$ Its site has background and papers on the potential economic impact in Asia. A human pandemic would be particularly catastrophic in developing countries where living conditions and malnutrition are likely to make people more vulnerable, health services are weak and vaccines and antivirals would be beyond reach. Even if there is no pandemic, bird flu will threaten the livelihoods of millions of people in Asia and Africa as health officials carry out mass poultry culling and other countries ban imports.

The news about anyone being afflicted in our country with the virus might stir panic among the population and play havoc with the poultry industry in particular. Fortunately timely measures taken by the Government could halt the spread of the disease, saved the poultry sector and prevent any human casualty. To face any future epidemic we should have regular publicity in the media to make people aware of the disease, well-trained health care personnel and stockpiled enough antiviral drug oseltamivir, commercially known as Tamiflu, may improve survival prospects if taken within 48 hours of symptoms appearing. ${ }^{36}$ Every effort must also be made to protect the poultry farms in Bangladesh. About 3.5 million people are employed in the poultry sector in Bangladesh that adds a value worth some Taka 50 billion or $\$ 833$ million to the country's GDP. Thus, if the epidemic breaks out among poultry birds here, culling of a very large number of birds will be required and that would invite ruin to this budding 
sector and leave considerable adverse effects on the economy. Furthermore, regular publicity needs to be done in the media to make people aware of the disease, to help prevent its spread.

\section{References:}

1. Giasuddin M, Alam J, Samad MA, Al-Mamun M, Taimur JFA. Highly Pathogenic Avian Influenza: Bangladesh Situation. Bangladesh Livestock Research Institute Web site. (Accessed September 28, 2007, at http://www.blri.gov.bd/banner_detail.php?bannerid=1)

2. Beigel JH, Farrar J, Han AM, Hayden FG, Hyer R, de Jong MD, et al. "Avian influenza A (H5N1) infection in humans". N Engl J Med 2005; 353: 1374-85.

3. FluTrackers.com. Bangladesh says no human case of bird flu. (Accessed September 28, 2007, at http://www. flutrackers.com/forum/showthread.php?t=19511)

4. Rahman M. Preparing for the next Influenza Pandemic: Bangladesh Perspective. Journal of Bangladesh College of Physicians and Surgeons 2007; 25: 53-5.

5. Centers for Disease Control and Prevention. Key Facts About Avian Influenza (Bird Flu) and Avian Influenza A (H5N1) Virus. (Accessed October 25, 2005, at http:/www.cdc.gov/flu/avian/gen-info/facts.htm)

6. Murphy BR, Webster RG: Orthomyxoviruses. In: Fields Virology 1996, (ed.): Fields BN, Knipe DM, Howley PM, Chanock RM, Melnick JL, Monath TP, Roizman B, Straus SE, 3rd ed., pp 1397-1445, Lippincott-Raven, Philadelphia, PA

7. Payungporn S, Chutinimitkul S, Chaisingh A, Damrongwantanapokin S, Nuansrichay B, Pinyochon W, et al. "Discrimination between Highly Pathogenic and Low Pathogenic H5 Avian Influenza A Viruses". Emerging Infectious Diseases 2006; 12: 700-1.

8. World Health Organization. Avian Influenza A (H5N1) situation (poultry) in Asia as at 2 March 2004: need for a long-term response, comparison with previous outbreaks. Wkly Epidemiol Rec 2004; 79: 96-9.

9. Hien TT, Liem NT, Dung NT, San LT, Mai PP, Chau NV et al. Avian Influenza A $(\mathrm{H} 5 \mathrm{~N} 1)$ in 10 patients in Vietnam. N Engl J Med 2004; 350: 1179-88.

10. Chotpitayasunondh T, Ungchusak K, Hanshaoworakul W, Chunsuthiwat S, Sawanpanyalert P, Kijphati R, et al. Human disease from Influenza A (H5N1), Thailand, 2004. Emerging Infectious Diseases 2005; 11: 201-9.

11. Webster RG, Govorkova EA. "H5N1 Influenza Continuing Evolution and Spread". N Engl J Med 2006; 355: 2174-7.

12. Keawcharoen J, Oraveerakul K, Kuiken T, Fouchier RAM, Amonsin A, Payungporn S, et al. Avian Influenza H5N1 in tigers and leopards. Emerging Infectious Diseases 2004; 10 : 2189-91.
13. Harder TC, Werner O. "Avian Influenza", In: Influenza Report 2006, (ed.): Kamps BS, Hoffman C, Preiser W. Paris, France: Flying Publisher. ISBN 3-924774-51-X.

14. Chan PK. Outbreak of Avian Influenza A (H5N1) virus infection in Hong Kong in 1997. Clin Infect Dis 2002; 34 S58-S64.

15. Claas EC, Osterhaus $\mathrm{AD}$, van Beek R, De Jong JC, Rimmelzwaan GF, Senne DA, et al. Human Influenza A $\mathrm{H} 5 \mathrm{~N} 1$ virus related to a highly pathogenic avian influenza virus. Lancet $1998 ; 351: 460-1$.

16. Ungchusak K, Auewarakul P, Dowell SF, Kitphati R, Auwanit W, Puthavathana P, et al. Probable person-toperson transmission of Avian Influenza A (H5N1). N Eng J Med 2005; 352: 333-40.

17. Centers for Disease Control and Prevention. Cases of Influenza A (H5N1) - Thailand, 2004. MMWR Morb Mortal Wkly Rep 2004; 53:100-3.

18. Reuters AlertNet - Bird flu: Threat of a global pandemic. 2007. (Accessed June 13, 2007, at http://www.alertnet.org/db/crisisprofiles/BIRDFLU.htm?v= in_detail)

19. The World Health Organization Global Influenza Program Surveillance Network. "Evolution of H5N1 Avian Influenza viruses in Asia". Emerging Infectious Diseases 2005; 11 : 1515-21.

20. Yuen KY, Chan PK, Peiris M, Tsang DN, Que TL, Shortridge KF, et al. Clinical features and rapid viral diagnosis of human disease associated with Avian Influenza A H5N1 virus. Lancet 1998; 351: 467-71.

21. Lee M, Chang $\mathrm{P}$, Shien J, Cheng M, Shieh HK. Identification and sub typing of Avian Influenza viruses by reverse transcription-PCR. J Virol Methods 2001; 97: 13-32.

22. Ng EKO, Cheng PKC, Ng AYY, Hoang TL, Lim WWL. Influenza A H5N1 detection. Emerging Infectious Diseases 2005; 11: 1303-5.

23. World Health Organization. Recommended laboratory tests to identify Influenza A/H5 virus in specimens from patients with an influenza-like illness. 2005. (Accessed September 2, 2005 , http://www.who.int/csr/disease/avian_influenza/guidelines/ avian_labtests1.pdf.)

24. Govorkova EA, Leneva IA, Goloubeva OG, Bush K, Webster RG. Comparison of efficacies of RWJ-270201, zanamivir, and oseltamivir against H5N1, H9N2, and other Avian Influenza viruses. Antimicrob Agents Chemother 2001; 45: 2723-32.

25. Cooper NJ, Sutton AJ, Abrams KR, Wailoo A, Turner D, Nicholson KG. Effectiveness of neuraminidase inhibitors in treatment and prevention of Influenza A and B: systematic review and meta-analyses of randomized controlled trials. BMJ 2003; 326: 1235. 
26. Belshe RB, Burk B, Newman F, Cerruti RL, Sim IS. Resistance of Influenza A virus to amantadine and rimantadine: results of one decade of surveillance. J Infect Dis 1989; 159: 430-5.

27. Webster RG, Walker EJ. "The world is teetering on the edge of a pandemic that could kill a large fraction of the human population". American Scientist 2003; 91: 122.

28. Allen PJ. The world awaits the next pandemic: will it be H5N1, the 'bird flu'? J Child Health Care 2006; 10: 178-87.

29. Schultz J. Bird flu vaccine won't precede pandemic. United Press International Web site. (Accessed February 4, 2006, at http://www.upi.com/ConsumerHealthDaily/view.php?Story ID=20051128-054641-9412r)

30. World Health Organization. Antigenic and genetic characteristics of $\mathrm{H} 5 \mathrm{~N} 1$ viruses and candidate $\mathrm{H} 5 \mathrm{~N} 1$ vaccine viruses developed for potential use as pre-pandemic vaccines. (Accessed August 18, 2006, at http://www. who.int/csr/disease/avian_influenza/guidelines/h5n1virus2 006_08_18/en/index.html)
31. Mounts AW, Kwong H, Izurieta HS, Ho Y, Au T, Lee M, et al. Case-control study of risk factors for Avian Influenza A (H5N1) disease, Hong Kong, 1997. J Infect Dis 1999; 180: 505-8.

32. US Food and Drug Administration. What Consumers Need to Know About Avian Influenza? (Accessed October 19, 2006, at http://www.cfsan.fda.gov/ dms/avfluqa.html)

33. Centers for Disease Control and Prevention. Update: notice to travelers about Avian Influenza A (H5N1). July 29, 2005. (Accessed September 2, 2005, at http://www.cdc.gov/ travel/other/avian_flu_ah5n1_031605.htm.)

34. World Health Organization. Avian Influenza - fact sheet. (Accessed January 15, 2004, at http://www.who.int/ csr/don/2004_01_15/en/)

35. Asian Development Bank report: Bird flu could drastically impact Asian economies. (Accessed November 4, 2005, at http://www.birdfludefense.com/012963.html)

36. Ward P, Small I, Smith J, Suter P, Dutkowski R. Oseltamivir (Tamiflu) and its potential for use in the event of an influenza pandemic. J Antimicrob Chemother 2005; 55: Suppl 1:i5-i21. 